University of South Carolina

Scholar Commons

4-2009

\title{
Soil zinc content, groundwater usage, and prostate cancer incidence in South Carolina
}

\author{
Sara E. Wagner \\ University of South Carolina - Columbia \\ James B. Burch \\ University of South Carolina - Columbia \\ Jim Hussey \\ University of South Carolina - Columbia \\ Tom Temples
}

Susan Bolick-Aldrich

See next page for additional authors

Follow this and additional works at: https://scholarcommons.sc.edu/

sph_epidemiology_biostatistics_facpub

Part of the Public Health Commons

\section{Publication Info}

Postprint version. Published in Cancer Causes and Control, Volume 20, Issue 3, 2009, pages 345-353. Wagner, S.E., Burch, J.B., Hussey, J., Temples, T., Bolick-Aldrich, S., Mosley-Broughton, C., . . Hébert, J.R. (2009). Soil zinc content, groundwater usage, and prostate cancer incidence in South Carolina. Cancer Causes and Control, 20(3), 345-353. doi: 10.1007/s10552-008-9248-0

(c) 2008 Springer Science+Business Media B.V.

The final publication is available at www.springerlink.com.

This Article is brought to you by the Epidemiology and Biostatistics at Scholar Commons. It has been accepted for inclusion in Faculty Publications by an authorized administrator of Scholar Commons. For more information, please contact digres@mailbox.sc.edu. 


\section{Author(s)}

Sara E. Wagner, James B. Burch, Jim Hussey, Tom Temples, Susan Bolick-Aldrich, Catishia Mosley-

Broughton, Yuan Liu, and James R. Hébert 


\title{
Soil zinc content, groundwater usage, and prostate cancer incidence in South Carolina
}

\author{
Sara E. Wagner, \\ Cancer Prevention and Control Program, University of South Carolina, 2221 Devine Street, Suite \\ 222, Columbia, SC 29208, USA. Arnold School of Public Health, Department of Epidemiology and \\ Biostatistics, University of South Carolina, Columbia, SC, USA
}

\begin{abstract}
James B. Burch,
Cancer Prevention and Control Program, University of South Carolina, 2221 Devine Street, Suite 222, Columbia, SC 29208, USA. Arnold School of Public Health, Department of Epidemiology and Biostatistics, University of South Carolina, Columbia, SC, USA

\section{Jim Hussey,}

Arnold School of Public Health, Department of Epidemiology and Biostatistics, University of South Carolina, Columbia, SC, USA

\section{Tom Temples,}

Advanced Environmental Solutions, LLC, Lexington, SC, USA

\author{
Susan Bolick-Aldrich, \\ Department of Health and Environmental Control, South Carolina Central Cancer Registry, \\ Columbia, SC, USA
}

\section{Catishia Mosley-Broughton,}

Department of Health and Environmental Control, South Carolina Central Cancer Registry, Columbia, SC, USA

Yuan Liu, and

Arnold School of Public Health, Department of Epidemiology and Biostatistics, University of South Carolina, Columbia, SC, USA

\section{James R. Hebert}

Cancer Prevention and Control Program, University of South Carolina, 2221 Devine Street, Suite 222, Columbia, SC 29208, USA. Arnold School of Public Health, Department of Epidemiology and Biostatistics, University of South Carolina, Columbia, SC, USA

Sara E. Wagner: wagnerse@mailbox.sc.edu

\section{Abstract}

Background-Prostate cancer (PrCA) incidence in South Carolina (SC) exceeds the national average, particularly among African Americans (AAs). Though data are limited, low environmental zinc exposures and down-regulation of prostatic zinc transporter proteins among AAs may explain, in part, the racial PrCA disparity.

Methods-Age-adjusted PrCA rates were calculated by census tract. Demographic data were obtained from the 1990 census. Hazardous waste site locations and soil zinc concentrations were obtained from existing federal and state databases. A geographic information system and Poisson 
regression were used to test the hypothesis that census tracts with reduced soil zinc concentrations, elevated groundwater use, or more agricultural or hazardous waste sites had elevated PrCA risks.

Results-Census tracts with high groundwater use and low zinc concentrations had higher PrCA rate ratios (RR: $1.270 ; 95 \%$ confidence interval: 1.079, 1.505). This effect was not more apparent in areas populated primarily by AAs.

Conclusion-Increased PrCA rates were associated with reduced soil zinc concentrations and elevated groundwater use, although this observation is not likely to contribute to SC's racial PrCA disparity. Statewide mapping and statistical modeling of relationships between environmental factors, demographics, and cancer incidence can be used to screen hypotheses focusing on novel PrCA risk factors.

\section{Keywords}

South Carolina; Cancer statistics; Race; Geographic information systems; Disparities

\section{Introduction}

Prostate cancer $(\operatorname{PrCA})$ is the most frequently diagnosed cancer in the United States [1]. Nationwide, PrCA incidence is greater among African-American (AA) compared with European-American (EA) or Asian-American men [2,3]. South Carolina (SC), which is composed of approximately $29 \%$ AAs and $67 \%$ EAs [4], is unique in its racial disparity in PrCA incidence and mortality. PrCA incidence in SC is $>75 \%$ higher among AA men compared with EA men, whereas the national differential is $\approx 60 \%$ [5]. In addition, the PrCA mortality rate among AAs residing in $\mathrm{SC}(76.7$ per 100,000) is consistently one of the highest in the world, and is 2.81 times higher than PrCA mortality among EA men in SC [5]. While the proportion of men screened for PrCA in SC via digital rectal examination is somewhat lower among AAs (75\%) compared with EAs (85\%), screening rates using prostate-specific antigen (PSA) are similar among AAs and EAs (both 66\% in 2004), with no major differences noted over time [6]. In SC, $17 \%$ of AA men are diagnosed at a late stage (regional/distant) compared to $12 \%$ of EA men; AA men also tend to have tumors with a higher pathological grade compared to EA men in SC [6]. The only firmly established risk factors for PrCA are increasing age, a family history of the disease, and AA race [7]. Results from studies attempting to identify other PrCA risk factors have been equivocal [6,8]. Potential risk factors include: factors related to socioeconomic status including education, literacy, and financial resources; genetic and androgenic factors; exposure to certain environmental agents including chemical constituents from hazardous waste sites, pesticide use and farming, some toxic heavy metals (e.g., cadmium, uranium); and dietary factors including reduced intake of some essential trace elements (e.g., zinc, selenium) [7,9-16]. There is a clear need to evaluate potential environmental factors or combinations of factors that may be responsible for elevated rates of PrCA among residents in the United States and other Western countries, especially among AAs in SC.

Zinc may play a role in intensifying PrCA susceptibility [17]. In a normal prostate, zinc levels accumulate naturally [18] to inhibit citrate oxidation and to induce apoptosis $[19,20]$.

Impairment of zinc accumulation is associated with reduced prostatic zinc concentrations, and with prostate tumor growth in vitro [19]. Because AAs may have evolutionarily downregulated a specific type of zinc transporter to avoid toxicity in zinc-rich ancestral West African soils, it is conceivable that individuals with this characteristic phenotype have an impaired ability to incorporate zinc into the prostate [21]. Although the evidence is somewhat limited, these observations suggest that zinc transporter down-regulation may explain, at least in part, elevated PrCA rates among AA men. 
There are multiple pathways by which humans may be exposed to zinc, one of which is leaching of soil zinc into groundwater [22]. There are many factors that can influence zinc mobility in soil including solubility, capacity for cation exchange, soil $\mathrm{pH}$, redox potential, zinc concentrations, soil:solution mass ratio, groundwater contact time, and the chemical species found in soil [23-25]. In general, however, metal concentrations in groundwater tend to be derived from surrounding soils [25].

The purpose of this study was to examine the role of environmental factors, including groundwater use and soil zinc concentrations, on PrCA rates among AA and EA populations in SC. Specifically, we sought to test the hypothesis that census tracts with low concentrations of soil zinc are associated with higher PrCA rates, and that this relationship is stronger in areas with more AA men compared to areas populated primarily by EAs. We used a geographic information system (GIS) to characterize soil zinc concentrations, groundwater consumption, agricultural land use, hazardous waste site locations, and PrCA cases in SC. Spatial statistical modeling was used to evaluate the relationship between PrCA cases and environmental factors. To evaluate their potential link with racial PrCA disparities in SC, we not only performed analyses among all incident cases in SC from 1996 to 2002, but also performed analyses among men grouped into areas with predominantly AA or EA populations.

\section{Methods}

GIS ArcMAP software version 9.1 (ESRI, Redlands, CA) was used to combine data from the following sources: PrCA cases from the SC Central Cancer Registry (SCCCR); demographic information from the United States Census Bureau; and soil zinc data from the SC Department of Health and Environmental Control (DHEC), United States Geological Survey (USGS)

PLUTO, and Clemson University databases. The age distribution, proportion of AAs, median household income, number of agricultural areas, and the proportion of individuals using groundwater as their main water source were obtained, by census tract, from 1990 United States Census Bureau data [26]. The 1990 census was selected because: (1) the percentage of the population using groundwater was obtained only in this year, and (2) it allowed for a latency of six- to twelve-years prior to assessing the relationship between potential population exposures and PrCA incidence. The number of hazardous waste sites within each census tract listed under the Comprehensive Environmental Response, Compensation, and Liability Act (CERCLA) was obtained from United States Environmental Protection Agency (EPA) data [27].

Soil zinc concentrations in parts per million (ppm) were obtained from the SC DHEC $(0.3 \%)$, PLUTO (0.1\%), and Clemson University $(99.6 \%)$ databases. The SC DHEC database $(n=253$ samples) is composed of soil samples collected by SC DHEC and EPA personnel between 1985 and 1995; 71\% were collected from surface soil, $11 \%$ from shallow subsurface soil, and $18 \%$ from deep soil. SC DHEC and private laboratories analyzed these samples using standardized inductively coupled plasma (ICP), atomic absorption furnace, and atomic absorption direct aspiration methods [28]. The PLUTO database ( $n=78$ samples) contains inorganic geochemical data from the analytical laboratories of the Geologic Division of USGS. Samples were collected and analyzed beginning in 1960 and ending in 1995 to support a number of USGS programs. Zinc data contained in the Clemson University database $(n=79,055$ samples) originate from soil samples collected from residential and occupational yard, farm, and other land areas sent to Clemson University Soil Testing Laboratory for content analysis. Soil zinc concentrations were determined by ICP atomic emission spectrometry using a standardized protocol that included established quality control procedures. This laboratory participates in the North America Proficiency Testing soil sample exchange program, which allows for comparison of its analytical techniques and data with those from other laboratories to ensure data accuracy and reliability [29]. Five Clemson University soil data files (2001- 
2005) containing addresses but not sample latitude and longitude were geocoded using the State e911 center line file as the reference layer [30], and then assigning a census tract to each sample address. Only automatic batch matching (i.e., no manual interactive matching) was used, and the final data set from this source included only Tier five matches (i.e., matched to the exact address) to maximize data accuracy. Zinc concentrations at each sample location were assigned to a census tract using the sample latitude and longitude or address, and spatially joining them with the $1990 \mathrm{SC}$ census tract boundary shapefile [31].

Geometric mean zinc concentrations were determined by averaging log transformed values for all soil samples within a given census tract. In accordance with USGS protocols, if the raw exposure data file included an observation of ' 0 ' for the concentration of an element ( $1 \%$ of all data), it was converted to half the value of the detection limit [32]. Census tracts with a missing zinc concentration were assigned the average of its neighboring tracts $(n=52 ; 6 \%$ of all SC census tracts).

All PrCA cases diagnosed in SC between 1 January 1996 and 31 December 2002 were registered with the SCCCR according to standardized procedures [33]. The SCCCR has datasharing agreements with 20 states in order to ensure that the vast majority of incident cases are recorded. Since its inception in 1996, the SCCCR has consistently received the highest rating for data completeness (>97.5\%), timeliness, and quality from the North American Association of Central Cancer Registries. A peak in PrCA incidence occurred in the early 1990's due to the implementation of PSA screening [34,35], although PrCA rates among both AA and EA men in SC were stable during the period of study, with slight decreases in more recent years [6]. Additionally, the population age structure of SC did not change significantly in the last decade [36]. The residential latitude and longitude at date of diagnosis for each PrCA case was spatially joined to the 1990 census tract boundary shapefile to determine the residential census tract for each case. Age adjustment of PrCA incidence was conducted via the indirect method [37], using statewide age-specific PrCA incidence rates among males over 40 years of age and the age-specific population distribution within each census tract for the year 1990. Standardized incidence ratios (SIRs) with 95\% confidence intervals (CIs) were calculated for each tract using the statewide age-adjusted PrCA incidence rate (1996-2002) as the standard [38]. PrCA SIRs and soil zinc concentrations were then mapped by census tract to illustrate the extent of their spatial overlap.

\section{Statistical analysis}

Separate spatial Poisson regression models were used to assess the effects of soil zinc concentrations, groundwater use, agricultural land use, and the number of hazardous waste sites on new PrCA cases during the study period, after adjusting for spatial variation, median household income, and race. The dependent variable in all models was the number of PrCA cases with an offset variable included in each model to account for the age-adjusted expected number of cases. Thus, the standardizations in these models target the expected case numbers, allowing for the use of simple counts as the dependent variable. Separate analyses focused on areas with elevated groundwater use in combination with zinc or other exposure factors or with race to determine their impact on new PrCA cases. The relationship between PrCA incidence and soil zinc concentrations was assessed using zinc either as a continuous variable or as a categorical variable with several different cut points. The cut points presented below were chosen to attain large enough group sizes to optimize potential dose-response relationships and to ensure that the statistical models would converge. Interpretation of the results was not altered by analyses that used different cut points. We assumed the standard zero-mean Gaussian prior distribution for uncorrelated heterogeneity, a conditional autoregressive (CAR) prior distribution for correlated heterogeneity, and included an adjacency matrix in the statistical model to account for the spatial distribution of census tract neighbors. To create the adjacency 
matrix, the GIS-readable shapefile of SC census tract boundaries was converted to WinBUGSreadable S-PLUS format using the transformation tool, maps2WinBUGS version 1.1.3 [39]. Posterior distributions were obtained using Bayesian modeling techniques with WinBUGS software version 1.4.1 (Imperial College and Medical Research Council, UK). Markov chain Monte Carlo (MCMC) simulation was used to perform posterior sampling, and convergence was assessed by monitoring the history, density, and autocorrelation plots. Convergence was reached after 15,000 iterations for all models. Rate ratios (RRs) were generated for each association and the statistical significance was assessed using 95\% CIs.

\section{Results}

Characteristics of the SC PrCA cases and census tracts included during the study period are presented in Table 1. Of the original 20,933 PrCA cases diagnosed from 1996 to 2002, 17,665 (84\%) successfully produced a Tier 5 match to a 1990 census tract. Of the 3,268 (16\%) nonTier 5 matches, 2,820 (86\%) were Tier 9 matches, which indicates a match to a zip code centroid. Tier 5 and non-Tier 5 PrCA cases were similar in terms of tumor grade, stage, and age at diagnosis; however, $29 \%$ of the Tier 5 matches were AA while $44 \%$ of the non-Tier 5 matches were AA. Of the original 169,443 zinc soil samples from the Clemson University databases, 79,055 (47\%) were successfully geocoded at the Tier 5 level to a 1990 SC census tract. The statewide average (standard deviation) of soil zinc concentrations in this study was 13.5 (46.6) ppm. For comparison, soil zinc concentrations in the conterminous United States range from $<5$ to $2,900 \mathrm{ppm}$, with an average concentration of $60 \mathrm{ppm}$ [22].

When each factor was evaluated independently, there were modest increases in PrCA risk among SC census tracts with an increasing number of agricultural or CERCLA sites or with decreasing soil zinc concentrations. However, none of these associations attained statistical significance (Table 2). There were 81 census tracts (9\%) that had both a higher than expected PrCA SIR and median soil zinc concentrations that were below the statewide geometric mean (Fig. 1). The combined effects of groundwater use, soil zinc concentrations, and agricultural or hazardous waste sites on PrCA occurrence are presented in Table 3. In tracts with elevated groundwater usage, low zinc concentrations were associated with an increased PrCA risk (RR: 1.270; 95\% CI: 1.079, 1.505; Table 3). In areas with low groundwater use, there was no statistically significant relationship between zinc concentrations and PrCA (data not shown). An increase in the number of agricultural or hazardous waste sites among census tracts with elevated groundwater use did not influence PrCA risk (Table 3). The proportion of AAs among census tracts with high groundwater use was approximately $38 \%$, whereas tracts with low groundwater use were composed of approximately $28 \%$ AAs (Fig. 2).

The relationship between soil zinc and PrCA was further evaluated by stratifying census tracts with elevated groundwater use into categories with a low $(<34 \%)$ or high $(\geq 66 \%)$ proportion of AAs (Table 4). In areas populated primarily by EAs, low soil zinc concentrations were associated with a slight increase in PrCA case frequencies compared to high EA areas with elevated soil zinc and groundwater use. Among areas with elevated groundwater use that were populated primarily by AAs, there was a slight decrease in PrCA case frequencies among tracts with low soil concentrations. However, neither of these comparisons achieved statistical significance (Table 4).

\section{Discussion}

PrCA has few established risk factors, though there is strong evidence that environmental factors play an important role in explaining the large PrCA rate differences observed internationally $[40,41]$. Exposure to certain environmental agents may contribute to $\operatorname{PrCA}$ etiology $[14,15,17,42-44]$. The burden of disease tends to be much higher in AAs in the United 
States and is especially elevated in SC AAs [6]. Zinc may play a role in PrCA susceptibility [17]; low prostate zinc concentrations are associated with PrCA cell growth in vitro [19]. In many populations, diet may be the dominant vehicle for zinc exposure, although studies examining the relationship between zinc and PrCA risks via dietary exposures have yielded mixed results [15]. There is a paucity of information on environmental (i.e., non-dietary) zinc exposures and cancer risk [22].

This study used GIS and spatial statistical modeling to explore relationships between potential environmental risk factors and PrCA incidence in SC. In particular, we focused on groundwater consumption and a biologically plausible hypothesis linking reduced zinc intake with increased PrCA risk. Census tracts with elevated ground-water consumption and low soil zinc concentrations had increased PrCA rates. These results are consistent with other studies suggesting that elevated zinc intake is associated with reduced PrCA risk $[21,45,46]$. However, the hypothesis that the relationship between reduced soil zinc and elevated PrCA risk would be stronger among AA than EA men was not supported. One reason for this may have been that cadmium, another metal associated with PrCA risk, was not evaluated. Cadmium has a greater affinity than zinc for certain biochemical ligands; it can displace zinc due to its similar physical and chemical properties [47], inhibit zinc's dietary absorption [48], and impede its uptake by the prostate $[49,50]$. There was insufficient statewide coverage of cadmium to evaluate the effect of cadmium on PrCA risk in our study, although potential interactions between cadmium and zinc may have contributed to inaccuracy in the results that were obtained, and uncertainties in their interpretation.

Several other study strengths and limitations are noteworthy. The data sources that were combined to form the soil zinc data set have inherent measurement error and other sources of variability. However, the overall zinc coverage was dense, and potential problems associated with geocoding, such as positional inaccuracy and differential match rates by geographic region [51,52], were minimized through the use of only Tier 5 matches. Nonetheless, the introduction of some misclassification through the geocoding process for PrCA data was possible, and we noted that the proportion of AAs among non-Tier 5 matches (44\%) was larger than the percentage of AAs with Tier 5 addresses (29\%). However, non-Tier 5 matches represented a limited proportion (16\%) of all PrCA cases, and Tier 5 and non-Tier 5 PrCA cases were similar in terms of tumor grade, stage, and age at diagnosis. Among the non-Tier 5 matches, most were located in Claredon, Horry, and Williamsburg counties for both EA and AA men. These three counties, located in northeast $\mathrm{SC}$, are rural areas with relatively high groundwater consumption but with PrCA rates that were not associated with soil zinc concentrations (Figs. 1,2). The potential bias that may have been introduced is difficult to gauge but is likely minor because the spatial distribution and groundwater consumption pattern were similar among non-Tier 5 AAs and EAs.

A fundamental limitation inherent to this ecologic design is that data were not analyzed at the individual level. The soil zinc concentrations used for these analyses may not have been entirely representative of the total amount of zinc ingestion. For example, zinc intake also may occur through other sources, such as the diet or supplementation, which was not accounted for in these analyses. In populations that grow most of their own food, soil zinc concentrations could be important for assessing exposure and PrCA risk. Because dietary sources of zinc tend to be expensive [53,54], and incomes among some AA populations in SC can be low [36,55], it is conceivable that zinc could still be an important explanatory factor for the racial PrCA disparity in SC. Areas identified in Fig. 1 represent locations where this relationship might be more directly evaluated in future studies.

The linkage of several existing databases for this analysis, including the high quality SCCCR, allowed for relatively rapid and cost-effective screening of potential PrCA-related hypotheses 
with a reasonable latency between exposure and outcome. Census-derived population and environmental characteristics were both assessed for the year 1990, providing for a six- to twelve-year follow-up period of environmental exposure prior to PrCA diagnosis. The census tracts that were used as the unit of analysis were more advantageous than zip codes due to the potential for spatiotemporal discontinuity and changes in zip code boundaries [56,57]. Census tracts also provided for a finer level of analysis, making it possible to detect trends that may have been masked using broader geographic boundaries. Evaluation of cancer incidence among census tracts may result in unstable and unreliable estimates of age-adjusted rates. For this reason, the more stable statewide SC PrCA rates were used via the indirect method to estimate expected cases within each tract. Also, we did not account for in- or out-migration among census tracts during the study period. Although it is possible that some of our study population migrated during the time frame of interest, SC has a relatively stable population base [36], particularly among rural communities where groundwater use is more prevalent.

$\mathrm{SC}$ is a state with a heavy PrCA disease burden. The use of GIS with pre-existing data and spatial statistical modeling techniques serves as an efficient method for the evaluation of potential relationships between environmental risk factors and PrCA incidence. Results from this investigation suggest that PrCA rates may be elevated in areas with a combination of high groundwater use and reduced soil zinc concentrations. Other spatially aggregated environmental, demographic, behavioral, or social data can be similarly screened for potential associations with PrCA incidence using this approach.

\section{Acknowledgments}

Research Career Development Award, Department of Veteran's Affairs VISN-7, Charleston, South Carolina to J. B. B.; National Cancer Institute, Community Networks Program (1 U01 CA114601-01 to J. R. H.).

\begin{tabular}{|c|c|}
\hline PrCA & Prostate cancer \\
\hline SC & South Carolina \\
\hline $\mathbf{A A}$ & African-American \\
\hline EA & European-American \\
\hline PSA & Prostate-specific antigen \\
\hline GIS & Geographic information system \\
\hline $\mathbf{R R}$ & Rate ratio \\
\hline SCCCR & South Carolina Central Cancer Registry \\
\hline DHEC & Department of Health and Environmental Control \\
\hline USGS & United States Geological Survey \\
\hline CERCLA & Comprehensive Environmental Response, Compensation, and Liability Act \\
\hline EPA & Environmental Protection Agency \\
\hline ppm & Parts per million \\
\hline ICP & Inductively coupled plasma \\
\hline SIR & Standardized incidence ratio \\
\hline CI & Confidence interval \\
\hline CAR & Conditional autoregressive \\
\hline
\end{tabular}


MCMC Markov chain Monte Carlo

\section{References}

1. Jemal A, Siegel R, Ward E, Murray T, Xu J, Thun MJ. Cancer statistics. CA Cancer J Clin 2007;57 (1):43-66. [PubMed: 17237035]

2. Morton RA. Racial differences in adenocarcinoma of the prostate in North American men. Urology 1994;44(5):637-642.10.1016/S0090-4295(94)80196-7 [PubMed: 7526522]

3. Pienta KJ, Demers R, Hoff M, Kau TY, Montie JE, Severson RK. Effect of age and race on the survival of men with prostate cancer in the metropolitan Detroit tricounty area, 1973 to 1987 . Urology 1995;45 (1):93-100.10.1016/S0090-4295(95)96996-9 [PubMed: 7817485]

4. United States Census Bureau American Community Survey. Data profile highlights. South Carolina: 2006.

5. US Cancer Statistics Working Group. United States Cancer Statistics: 2004 Incidence and Mortality. US DHHS/CDC/NIH-NCI; Atlanta, GA: 2007.

6. Drake BF, Keane TE, Mosley CM, et al. Prostate cancer disparities in South Carolina: early detection, special programs, and descriptive epidemiology. J S C Med Assoc 2006;102:241-249. [PubMed: 17319238]

7. Allen NE, Sauvaget C, Rodddam AW, et al. A prospective study of diet and prostate cancer in Japanese men. Cancer Causes Control 2004;15:911-920.10.1007/s10552-004-1683-y [PubMed: 15577293]

8. Hebert JR, Ghumare SS, Gupta PC. Stage at diagnosis and relative differences in breast and prostate cancer incidence in India: and comparison to the United States. Asian Pac J Cancer Prev 2006;7(6): 547-555. [PubMed: 17250425]

9. Thompson IM, Tangen CM, Tolcher A, Crawford ED, Eisenberger M, Moinpour CM. Association of African-American ethnic background with survival in men with metastatic prostate cancer. J Nat Cancer Inst 2001;93:219-225.10.1093/jnci/93.3.219 [PubMed: 11158191]

10. Deutsch E, Maggiorella L, Eschwege P, Bourhis J, Soria JC, Abdulkarim B. Environmental, genetic, and molecular features of prostate cancer. Lancet 2004;5:303-313.10.1016/S1470-2045(04)01468-8

11. Gilligan T. Social disparities and prostate cancer: mapping the gaps in our knowledge. Cancer Causes Control 2005;16:45-53.10.1007/s10552-004-1291-x [PubMed: 15750857]

12. Sanderson M, Coker AL, Logan P, Zheng W, Fadden MK. Lifestyle and prostate cancer among older African-Americans and Caucasian men in South Carolina. Cancer Causes Control 2004;15:647655.10.1023/B:CACO.0000036172.63845.d4 [PubMed: 15280622]

13. Hsieh K, Albersten PC. Populations at high risk for prostate cancer. Urol Clin N Am 2003;30:669676.10.1016/S0094-0143(03)00058-2

14. Faroon OM, Williams M, O'Connor R. A review of the carcinogenicity of chemicals most frequently found at National Priorities List sites. Toxicol Ind Health 1994;10(3):203-230. [PubMed: 7855869]

15. Navarro Silvera SA, Rohan TE. Trace elements and cancer risk: a review of the epidemiologic evidence. Cancer Causes Control 2007;18(1):7-27.10.1007/s10552-006-0057-z [PubMed: 17186419]

16. Bostwick DG, Burke HB, Djakiew D, et al. Human prostate cancer risk factors. Cancer 2004;101(10 Suppl):2371-2490.10.1002/cncr.20408 [PubMed: 15495199]

17. Franklin RB, Costello LC. Zinc as an anti-tumor agent in prostate cancer and in other cancers. Arch Biochem Biophys 2007;463(2):211-217.10.1016/j.abb.2007.02.033 [PubMed: 17400177]

18. Costello LC, Liu Y, Zou J, Franklin RB. Evidence for a zinc uptake transporter in human prostate cancer cells which is regulated by prolactin and testosterone. J Biol Chem 1999 June 18;274:17499_ 17504. [PubMed: 10364181]

19. Franklin RB, Feng P, Milon B, et al. hZIP1 zinc uptake transporter down regulation and zinc depletion in prostate cancer. Mol Cancer 2005;4(32):1-13. [PubMed: 15644144]

20. Iguchi K, Hamatake M, Ishida R, et al. Induction of necrosis by zinc in prostate carcinoma cells and identification of proteins increased in association with this induction. Eur J Biochem 1998;253:766770.10.1046/j.1432-1327.1998.2530 766.x [PubMed: 9654077] 
21. Rishi I, Baidouri H, Abbasi JA, et al. Prostate cancer in African-American men is associated with down-regulation of zinc transporters. Appl Immunohistochem Mol Morphol 2003;11:252-260.

22. [ATSDR] Agency for Toxic Substances and Disease Registry. Toxicological profile for zinc. U.S. Department of Health and Human Services, Public Health Service; 2005.

23. Environmental Protection Agency (EPA). EPA440481016 PB85212009. U.S. Environmental Protection Agency, Office of Water Regulations and Standards (WH-553); Washington, DC: 1980. Exposure and risk assessment for zinc.

24. Kalbasi M, Racz GJ, Lewen-Rudgers LA. Reaction products and solubility of applied zinc compounds in some Manitoba soils. Soil Sci Soc Am 1978;125:55-64.

25. Apak, R. Encyclopedia of surface and colloid science. Taylor and Francis; 2006. Adsorption of heavy metal ions on soil surfaces and similar substances: theoretical aspects; p. 484-509.

26. van der Cruijsen-Koeter IW, Vis AN, Roobol MJ, et al. Comparison of screen detected and clinically diagnosed prostate cancer in the European randomized study of screening for prostate cancer, section Rotterdam. J Urol 2005;174(1):121-125.10.1097/01.ju.0000162061.40533.0f [PubMed: 15947595]

27. Environmental Protection Agency (EPA). Human health evaluation manual, Part A. Interim Final. Vol. 1. Office of Emergency and Remedial Response; 1989 Dec. Risk assessment guidance for superfund.

28. Canova JL. Elements in South Carolina inferred background soil and stream sediment samples. S C Geol 1999;41:11-25.

29. Clemson University Extension: Agriculture Service Laboratory. http://www.clemson.edu/agsrvlb/index.htm

30. Polednak AP. Stage at diagnosis of prostate cancer in Connecticut by poverty and race. Ethn Dis 1997;7:215-220. [PubMed: 9467704]

31. South Carolina Census Shape File. Obtained from: South Carolina Department of Health and Environmental Control.

32. United States Geological Survey (USGS). Frequently Asked Questions concerning NURE HSSR Data.

33. South Carolina Central Cancer Registry Incidence and Mortality (SCCCR). Office of Public Health Statistics and Information Services. Department of Health and Environmental Control; 2006.

34. Chu KC, Tarone RE, Freeman HP. Trends in prostate cancer mortality among black men and white men in the United States. Cancer 2003;97(6):1507-1516.10.1002/cncr.11212 [PubMed: 12627516]

35. Liu L, Cozen W, Bernstein L, Ross RK, Deapen D. Changing relationship between socioeconomic status and prostate cancer incidence. J Natl Cancer Inst 2001;93(9):705-709.10.1093/jnci/93.9.705 [PubMed: 11333293]

36. SCBCB. South Carolina Statistical Abstract 2008. South Carolina Budget and Control Board, Office of Research and Statistics; Columbia, SC: 2008.

37. Rothman, KJ.; Greenland, S. Modern epidemiology. 2. Lippincott Williams \& Wilkins; Philadelphia: 1989.

38. Wilson EB, Hilferty MM. The distribution of chi-square. Proc Natl Acad Sci USA 1931;17:684688.10.1073/pnas.17. 12.684 [PubMed: 16577411]

39. Solymosi, N.; Reiczigel, J.; Harnos, A., et al. A Multitask PostGIS based Vet GIS Framework. 1st OIE International Conference Use of GIS in Veterinary Activities; October 2006; Silvi Marina, Abruzzo, Italy. 2006. http://epi.univet.hu/portal/sn/kutatas/epidemiologia/terbeli-epidemiologia/betegseg-terkepezes/ gisconference/oiegis.pdf

40. Hebert JR, Hurley TG, Olendzki B, Ma Y, Teas J, Hampl JS. Nutritional and socioeconomic factors in relation to prostate cancer mortality: a cross-national study. J Natl Cancer Inst 1998;90:16371647.10.1093/jnci/90.21.1637 [PubMed: 9811313]

41. Nelson WG, DeWeese TL, DeMarzo AM. The diet, prostate inflammation, and the development of prostate cancer. Cancer Metastasis Rev 2002;21:13-16.

42. Lichtenstein P, Holm NV, Verkasalo PK, et al. Environmental and heritable factors in the causation of cancer-analyses of cohorts of twins from Sweden, Denmark, and Finland. N Engl J Med 2000;343:78-85.10.1056/NEJM200007133430201 [PubMed: 10891514] 
43. Waalkes MP, Rehm S. Carcinogenicity of oral cadmium in the male-Wistar (WF/NCr) rat: effect of chronic dietary zinc deficiency. Fundam Appl Toxicol 1992;19:5-12.10.1016/0272-0590(92)90089$\mathrm{Z}$

44. Vogt TM, Ziegler RG, Graubard BI. Serum selenium and risk of prostate cancer in U.S. blacks and whites. Int J Cancer 2003;103:664-670.10.1002/ijc.10866 [PubMed: 12494476]

45. Elmes ME. Apoptosis in the small intestine of zinc-deficient and fasted rats. J Pathol 1977;123(4): 219-223.10.1002/path.1711230404 [PubMed: 592026]

46. Liang JY, Liu YY, Zou J, Franklin RB, Costello LC, Feng P. Inhibitory effect of zinc on human prostatic carcinoma cell growth. Prostate 1999;40(3):200-207.10.1002/(SICI)1097-0045(19990801) 40:3<200::AID-PROS8>3.0.CO;2-3 [PubMed: 10398282]

47. Achanzar WE, Diwan BA, Liu J, Quader ST, Webber MM, Waalkes MP. Cadmium-induced malignant transformation of human prostate epithelial cells. Cancer Res 2001;61:455-458. [PubMed: 11212230]

48. Lonnerdal B. Dietary factors influencing zinc absorption. J Nutr 2000;130:1378S-1383S. [PubMed: 10801947]

49. Reed JM, Stitch SR. The uptake of testosterone and zinc in vitro by the human benign hypertrophic prostate. J Endocrinol 1973;58(5):483-486.

50. Waalkes MP, Coogan TP, Barter RA. Toxicological principles of metal carcinogenesis with special emphasis on cadmium. Crit Rev Toxicol 1992;22(3,4):175-201. [PubMed: 1388705]

51. Oliver MN, Matthews KA, Siadaty M, Hauck FR, Pickle LW. Geographic bias related to geocoding in epidemiologic studies. Int J Health Geogr 2005;4:29.10.1186/1476-072X-4-29 [PubMed: 16281976]

52. Krieger N, Waterman P, Lemieux K, Zierler S, Hogan JW. On the wrong side of the tracts? Evaluating the accuracy of geocoding in public health research. Am J Public Health 2001;91(7):1114-1116. [PubMed: 11441740]

53. Le Marchand L, Kolonel LN, Hankin JH, Yoshizawa CN. Relationship of alcohol consumption to diet: a population-based study in Hawaii. Am J Clin Nutr 1989;49:567-572. [PubMed: 2923090]

54. The Nutrition Data System for Research (NDS-R Version 4.03_31). Nutrition Coordinating Center (NCC), University of Minnesota; Minneapolis, MN:

55. South Carolina Office of Research and Statistics. South Carolina Rural Health Report. SC Budget and Control Board; Columbia, SC: 2005.

56. Grubesic TH, Matisziw TC. On the use of ZIP codes and ZIP code tabulation areas (ZCTAs) for the spatial analysis of epidemiological data. Int J Health Geogr 2006;5:58.10.1186/1476-072X-5-58 [PubMed: 17166283]

57. Krieger N, Waterman P, Chen JT, Soobader MJ, Subramanian SV, Carson R. Zip code caveat: bias due to spatiotemporal mismatches between zip codes and US census-defined geographic areas-the Public Health Disparities Geocoding Project. Am J Public Health 2002;92(7):1100-1102. [PubMed: 12084688] 


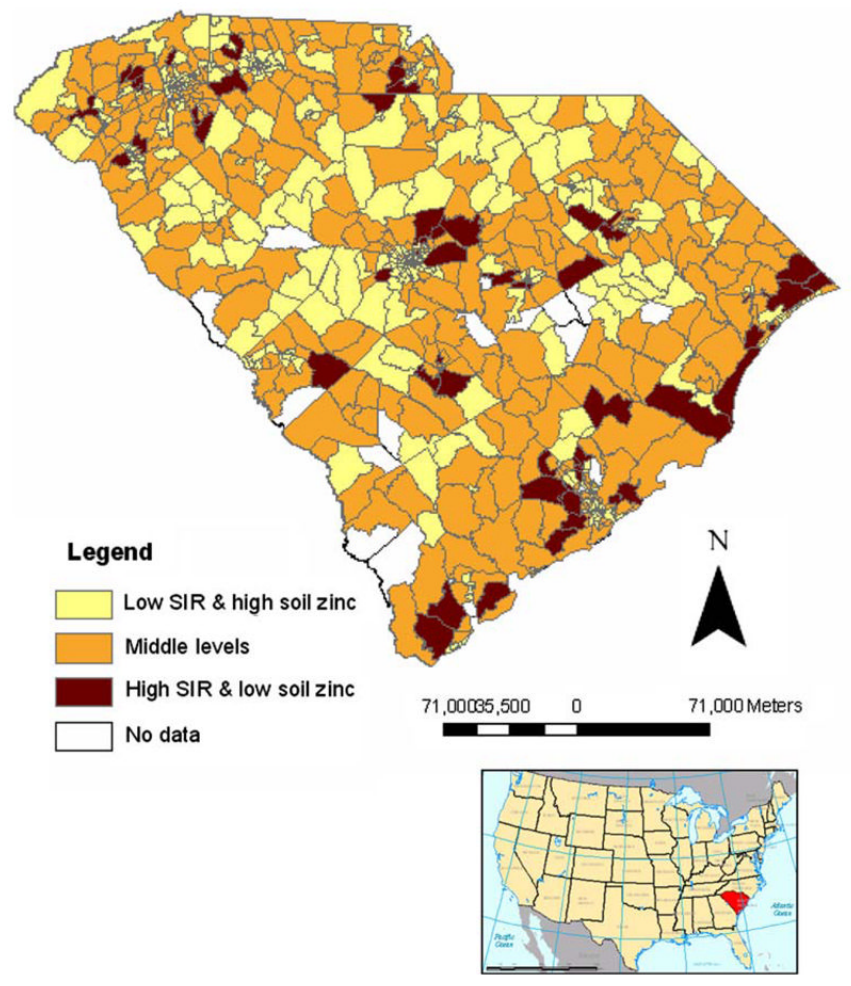

Fig. 1.

Seven-year (1996-2002) prostate cancer SIRs overlaid with median soil zinc concentration categories. High or low SIRs defined as having an age-standardized observed prostate cancer incidence greater or less than, respectively, those expected based on age-specific statewide rates. Significance was assessed by calculating $95 \%$ confidence intervals for SIRs within each census tract. High soil zinc is defined as greater than or equal to the median statewide concentration $(\geq 13.4 \mathrm{ppm})$; low soil zinc is defined as less than the median statewide concentration (<13.4 ppm). Inset map of United States highlighting South Carolina is included for reference 


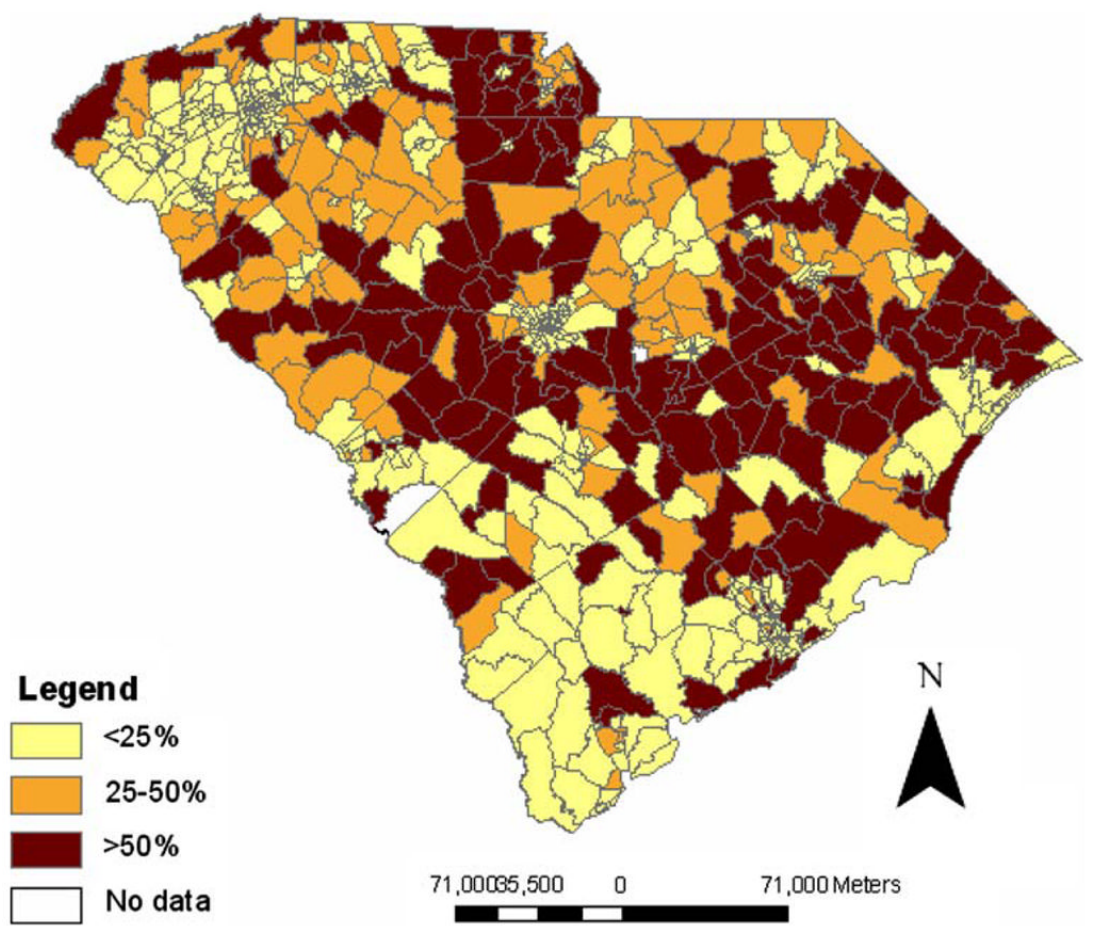

Fig. 2.

Percentage of per capita groundwater use in South Carolina by 1990 census tract 
Table 1

Characteristics of evaluable prostate cancer cases $(1996-2002, n=17,665)$ and census tracts $(1990, n=854)$ during study period

\begin{tabular}{|c|c|}
\hline Variable & Number $(\%)$ \\
\hline \multicolumn{2}{|l|}{ Individual-level characteristics } \\
\hline \multicolumn{2}{|l|}{ Race } \\
\hline African-American (Black) & $5,139(29)$ \\
\hline European-American (White) & $12,193(69)$ \\
\hline Other/unknown & $333(2)$ \\
\hline \multicolumn{2}{|l|}{ Disease stage at diagnosis } \\
\hline Localized & $12,894(73)$ \\
\hline Regional & $1,793(10)$ \\
\hline Distant/metastasized & $827(5)$ \\
\hline Unstageable/unknown & $2,151(12)$ \\
\hline \multicolumn{2}{|l|}{ Disease grade at diagnosis } \\
\hline Well differentiated & $1,177(7)$ \\
\hline Moderately differentiated & $11,579(66)$ \\
\hline Poorly differentiated & $3,175(18)$ \\
\hline Undifferentiated & $98(1)$ \\
\hline Not determined & $1,636(9)$ \\
\hline Age $(\text { mean } \pm \mathrm{SD})^{a}$ & $68 \pm 9$ \\
\hline \multicolumn{2}{|l|}{ Census tract-level characteristics } \\
\hline \multicolumn{2}{|l|}{ Groundwater use } \\
\hline Low $(<50 \%)$ & $682(80)$ \\
\hline High $(\geq 50 \%)$ & $172(20)$ \\
\hline \multicolumn{2}{|l|}{ No. of agricultural areas } \\
\hline Low $(<15)$ & $270(32)$ \\
\hline Medium (15-42) & $291(34)$ \\
\hline High $(>42)$ & $293(34)$ \\
\hline \multicolumn{2}{|c|}{ No. of hazardous waste (CERCLA) ${ }^{b}$ sites } \\
\hline 0 & $491(57)$ \\
\hline 1 & $196(23)$ \\
\hline 2 & $86(10)$ \\
\hline 3 & $40(5)$ \\
\hline$\geq 4$ & $41(5)$ \\
\hline
\end{tabular}


Table 2

Univariate models of covariates and exposures predicting PrCA incidence ${ }^{a}$ in SC, 1996-2002

\begin{tabular}{lll}
\hline Variables & $\mathbf{R R}^{\boldsymbol{b}}$ & $\mathbf{9 5 \%} \mathbf{C I}^{\boldsymbol{c}}$ \\
\hline No. of agriculture areas $^{d}$ & & \\
Low (<15) & Referent & - \\
Medium (15-42) & 1.026 & $0.952,1.108$ \\
High (> 42) & 1.033 & $0.944,1.129$
\end{tabular}

No. of hazardous waste $\left(\right.$ CERCLA) ${ }^{e}$ sites

$\begin{array}{lll}0 & \text { Referent } & - \\ 1 & 1.011 & 0.941,1.086 \\ 2 & 0.984 & 0.894,1.084 \\ 3 & 1.051 & 0.929,1.189 \\ \geq 4 & 1.055 & 0.929,1.192\end{array}$

Groundwater use $f$

\begin{tabular}{ccc} 
Low $(<50 \%)$ & Referent & - \\
High $(\geq 50 \%)$ & 0.941 & $0.862,1.026$ \\
Zinc concentration $g$ & 0.998 & $0.996,1.001$ \\
Zinc concentration ${ }^{2}$ & & \\
High (> 18.0 ppm) & Referent & - \\
Medium $(10.9-18.0$ ppm) & 1.070 & $0.990,1.159$ \\
Low (<10.9 ppm) & 1.061 & $0.979,1.151$ \\
\hline$a_{\text {Adjusted for median household income and race }(\% \text { AA) }}$ & \\
$b_{\text {Rate ratio }}$ & \\
$c_{\text {Confidence interval }}$ & \\
$d_{\text {Tertiles }}$ & \\
$e_{\text {Comprehensive Environmental Response, Compensation, and Liability Act }}$ & \\
$f_{\text {Based on } 50 \% \text { consumption split }}$ & \\
$g_{\text {Based on zinc concentration as a continuous variable }}$
\end{tabular}


Table 3

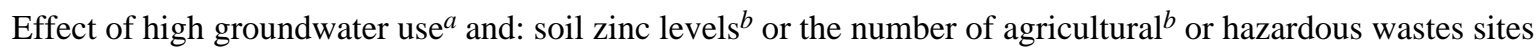
on PrCA incidence ${ }^{c}$ in SC, 1996-2002

\begin{tabular}{|c|c|c|c|}
\hline Variables & & $\mathbf{R R}^{d}$ & $95 \% \mathrm{CI}^{e}$ \\
\hline \multirow[t]{3}{*}{ High groundwater use and: } & No. of agricultural areas & & \\
\hline & Low $(<59 ; n=84)$ & Referent & - \\
\hline & High $(\geq 59 ; n=88)$ & 0.890 & $0.780,1.016$ \\
\hline \multirow[t]{3}{*}{ High groundwater use and: } & No. of hazardous waste (CERCLA) $f_{\text {sites }}$ & & \\
\hline & Low $(0 ; n=97)$ & Referent & - \\
\hline & $\operatorname{High}(\geq 1 ; n=75)$ & 0.897 & $0.792,1.014$ \\
\hline \multirow[t]{3}{*}{ High groundwater use and: } & Soil zinc concentrations (ppm) & & \\
\hline & High $(\geq 13.4$ ppm; $n=29)$ & Referent & - \\
\hline & Low $(<13.4 \mathrm{ppm} ; n=143)$ & 1.270 & $1.079,1.505$ \\
\hline \multicolumn{4}{|c|}{ Bold values refer to a statistically significant RR because th } \\
\hline \multicolumn{4}{|c|}{${ }^{a}$ Census tracts with $\geq 50 \%$ groundwater consumption only } \\
\hline \multicolumn{4}{|c|}{${ }^{b}$ Above or below median } \\
\hline \multicolumn{4}{|c|}{${ }^{c}$ Adjusted for median household income and race (\% AA) } \\
\hline \multicolumn{4}{|c|}{$d_{\text {Rate ratio }}$} \\
\hline$e_{\text {Confidence interval }}$ & & & \\
\hline
\end{tabular}


Table 4

Effect of high groundwater use ${ }^{a}$, race, and soil zinc ${ }^{b}$ levels on PrCA incidence ${ }^{c}$ in SC, 1996-2002

\begin{tabular}{|c|c|c|c|c|}
\hline Variables & & & $\mathbf{R R}^{d}$ & $95 \% \mathrm{CI}^{e}$ \\
\hline \multirow[t]{2}{*}{ High groundwater use } & Low $\%$ AA $(<36 \%)$ & High zinc $(\geq 13.4$ ppm; $n=13)$ & Referent & - \\
\hline & Low \% AA $(<36 \%)$ & Low zinc $(<13.4$ ppm; $n=72)$ & 1.007 & $0.875,1.157$ \\
\hline \multirow[t]{2}{*}{ High groundwater use } & High $\%$ AA $(\geq 64 \%)$ & High zinc $(\geq 13.4$ ppm; $n=16)$ & Referent & - \\
\hline & High \% AA ( $\geq 64 \%)$ & Low zinc $(<13.4 \mathrm{ppm} ; n=71)$ & 0.974 & $0.843,1.127$ \\
\hline
\end{tabular}

$a_{\text {Census tracts with } \geq 50 \% \text { groundwater consumption }}$

${ }^{b}$ Median value (ppm) split within racial categories

${ }^{c}$ Adjusted for median household income

$d_{\text {Rate ratio }}$

$e_{\text {Confidence interval }}$ 